\title{
TWO BRIEF FORMULATIONS OF BOOLEAN ALGEBRA
}

\section{LEE BYRNE}

This paper presents two new formulations of Boolean algebra which appear to have some direct interest on their own account, and which further take a place among the most economical versions, while also exhibiting more intuitive clarity than other versions of a similar degree of economy. ${ }^{1}$ As is to some extent customary in short expositions of this kind, I am taking for granted without formal presentation: (1) that the system contains more than one element; (2) that it is closed with respect to such operations as appear explicitly in the axioms; (3) that I may employ an identity (or equality) relation without formal statement of its properties; (4) that in addition I may utilize recognized principles of logic (in fact only an ordinary or elementary logic). With a view to comparisons I shall say that what I am presenting are the "transformation axioms." The variables $x, y, z, \cdots$ will represent elements. No other symbolism is required for features of the system except an accent ' and juxtaposition for an undefined singulary and binary operation respectively. A symbol for the class of elements is not introduced, because "formation" rules (for example, closure) are left informal. But certain further symbols are used in the formalism (and regarded as taken over from ordinary logic) to enable us to make our statements about the elements and operations (functions) of the system, either as axioms, theorems, or steps in proofs; these further symbols are an identity or equality sign $=$ (the only relation sign employed), and signs serving as connectives between our statements, namely $\&$ "and, " $\rightarrow$ "only if" or "if . . . then ... ," and $\leftrightarrows$ "if and only if." ${ }^{2}$ The last-named and the equality sign are the only ones appearing in axioms. Parentheses are used in customary ways. In the derivation of theorems indication is made of axioms and theorems used, except that Axioms II and III (associativity and commutativity) may sometimes be brought into play without explicit mention, and likewise certain frequently em-

Received by the editors October 21, 1945.

${ }^{1}$ Comparisons as to economy are intended to be limited to axiomatizations in mathematical (not metamathematical) language. The vague expression "intuitive clarity" here means that, in some familiar interpretation, the postulates adopted seem readily intelligible and plausible for a mind of limited mathematical experience.

${ }^{2}$ The " $\&$ " between statements is, of course, not to be confused with the "and" between elements, expressed by mere juxtaposition when we choose to interpret juxtaposition in the "and" rather than in the "or" manner (two ways in which it is feasible to interpret juxtaposition). 
ployed theorems (for example, 1, 2, 4, 5) after they have been proved. For simplicity of argument, no definitions are introduced.

\section{FORMUlation A}

\section{Axioms}

I. $x y^{\prime}=z z^{\prime} \leftrightarrows x y=x$.

II. $(x y) z=x(y z)$.

III. $x y=y x$.

\section{Theorems}

1. $x x=x$. From I (since $\left.x x^{\prime}=x x^{\prime}\right)$.

2. $x x^{\prime}=y y^{\prime}$. From 1 by $\mathrm{I}$.

3. $x y=x \& y z=y \rightarrow x z=x$.

ProOF. a. $x y=x \rightarrow(x y) z=x z$.

b. $y z=y \rightarrow(x y) z=x y$ by II.

c. $x y=x \& y z=y \rightarrow x z=x y=x$. From a, b.

4. $x^{\prime \prime}=x$.

Proof. a. $x^{\prime \prime} x^{\prime}=z z^{\prime}$. From 2 by III.

b. $x^{\prime \prime} x=x^{\prime \prime}$. From a by I.

c. $x^{\prime \prime \prime} x^{\prime}=x^{\prime \prime \prime}$. From b.

d. $x^{\prime \prime \prime \prime} x^{\prime \prime}=x^{\prime \prime \prime \prime}$. From b.

e. $x^{\prime \prime \prime \prime} x=x^{\prime \prime \prime \prime}$. From $\mathrm{d}, \mathrm{b}$ by 3 .

f. $x^{\prime \prime \prime \prime} x^{\prime}=z z^{\prime}$. From e by I.

g. $x^{\prime} x^{\prime \prime \prime}=x^{\prime}$. From $\mathrm{f}$ by III, I.

h. $x^{\prime \prime \prime}=x^{\prime}$. From c, g by III.

i. $x x^{\prime \prime \prime}=z z^{\prime}$. From 2 by h.

j. $x x^{\prime \prime}=x$. From $\mathrm{i}$ by $\mathrm{I}$.

k. $x^{\prime \prime}=x$. From $\mathrm{b}, \mathrm{j}$ by III.

5. $x\left(y y^{\prime}\right)=y y^{\prime}$.

Proof. a. $x\left(y y^{\prime}\right)=x\left(x x^{\prime}\right)$. From 2.

b. $x\left(y y^{\prime}\right)=x x^{\prime}$. From a by II, 1 .

c. $x\left(y y^{\prime}\right)=y y^{\prime}$. From b by 2 .

6. $x\left(x^{\prime} y\right)^{\prime}=x$.

Proof. a. $x\left(x^{\prime} y\right)=z z^{\prime}$. From 5 by II, III, 2.

b. $x\left(x^{\prime} y\right)^{\prime}=x$. Fom a by $4, \mathrm{I}$.

7. $x(x y)^{\prime}=x y^{\prime}$.

Proof. a. $x y^{\prime \prime}(x y)^{\prime}=z z^{\prime}$. From 2 by 4 .

b. $x y^{\prime}(x y)^{\prime}=x(x y)^{\prime}$. From a by I (and II, III). 
c. $x y^{\prime}(x y)^{\prime}=x y^{\prime}$. From 6 by 4 (and III).

d. $x(x y)^{\prime}=x y^{\prime}$. From b, c.

8. $\left(x^{\prime} y^{\prime}\right)^{\prime}\left(x^{\prime} y\right)^{\prime}=x$.

Proof. a. $x\left(x^{\prime} y^{\prime}\right)^{\prime}\left(x^{\prime} y\right)^{\prime}=x$. From 6 .

b. $x^{\prime}\left(x^{\prime} y^{\prime}\right)^{\prime}\left(x^{\prime} y\right)^{\prime}=x^{\prime} y\left(x^{\prime} y\right)^{\prime}=z z^{\prime}$. From 7, 4, and 2 .

c. $x\left(x^{\prime} y^{\prime}\right)^{\prime}\left(x^{\prime} y\right)^{\prime}=\left(x^{\prime} y^{\prime}\right)^{\prime}\left(x^{\prime} y\right)^{\prime}$. From b by I (and III, II).

d. $\left(x^{\prime} y^{\prime}\right)^{\prime}\left(x^{\prime} y\right)^{\prime}=x$. From c, a.

As it is well known that the axioms above have true interpretations in Boolean algebra, proof that they are necessary will be omitted. To show that they suffice for Boolean algebra, I have now derived from them a well attested set of transformation axioms for this algebra, known as Huntington's Fourth Set [4].3 The latter is worked out in terms of "not" and "or" operations. As I have left the present operations uninterpreted, I can at this point assign them the "not" and "or" characters to match Huntington's. Then his three transformation postulates appear here as Axioms II, III, and Theorem 8.

Incidentally, it would not be hard to show that each of Axioms I, II, III is independent of the two others.

\section{Formulation B}

Axioms

I. $x y^{\prime}=z z^{\prime} \leftrightarrows x y=x$.

II B. $(x y) z=(y z) x$.

Theorems

1. $x x=x$. From I (as before).

$2^{\prime} . x y=y x$.

PROOF. $x y=(x y)(x y)=(y(x y)) x=((x y) x) y=((y x) x) y=((x x) y) y$ $=(y y)(x x)=y x$. The first and last steps are from 1, the others from II B.

$3^{\prime} .(x y) z=x(y z)$.

PROOF. $(x y) z=(y z) x=x(y z)$. The first step from II B and the second from $2^{\prime}$.

Theorem $2^{\prime}$ is the previous Axiom III and Theorem $3^{\prime}$ the previous Axiom II. Thus in the presence of Axiom I the previous II and III could be replaced by Axiom II B. This is the only version known to the writer limited to two transformation axioms and employing the "not" and "and" or the "not" and "or" operations. No other choice of

${ }^{3}$ Numbers in brackets refer to the references cited at the end of the paper. 
operations seems to reach the level of intuitive clarity envisaged in this paper.

\section{REFERENCES}

1. H. M. Sheffer, $A$ set of five independent postulates for Boolean algebras, Trans. Amer. Math. Soc. vol. 14 (1913) pp. 481-488. This was the first version in which the transformation postulates numbered only three, then a very radical reduction (the other two were "formation" postulates on number of elements and closure). It also showed for the first time that the number of undefined concepts (operations) other than the class of elements could be reduced to one.

2. B. A. Bernstein, Simplification of the set of four postulates for Boolean algebras in terms of rejection, Bull. Amer. Math. Soc. vol. 39 (1933) pp. 783-787. In effect this reduces Sheffer's three transformation postulates to two, employing the same operation.

3. - A set of four postulates for Boolean algebras in terms of the "implicative" operation, Trans. Amer. Math. Soc. vol. 36 (1934) pp. 876-884. Another version in two transformation postulates.

4. E. V. Huntington, Nerw sets of postulates for the algebra of logic, Trans. Amer. Math. Soc. vol. 35 (1933) pp. 274-304, 557-558, 971. The fourth and fifth sets are limited to three transformation postulates.

5. S. Hoberman and J. C. C. McKinsey, $A$ set of postulates for Boolean algebra, Bull. Amer. Math. Soc. vol. 43 (1937) pp. 588-592. Has only one transformation postulate, but this is metamathematical in character, and equivalent to an infinite bundle of "object-language" axioms of the kind considered in this paper.4 See my Footnote 1.

\section{RUTGERS UNIVERSITY}

4 The metamathematical character might be in doubt in the published version, but the senior author has in correspondence suggested what he regards as a more satisfactory wording, which seems without question metamathematical. See also review by Alonzo Church in J. Symbolic Logic vol. 2 (1937) pp. 172-173. 